\title{
Editorial Review:
}

\section{Kant and Contemporary Epistemology}

\author{
GRAHAM BIRD \\ University of Manchester
}

The editors of Kantian Review thought it appropriate to offer some account of the journal's policy aims in its initial issues. The journal was from the first intended to provide a forum for discussion of Kant's philosophy with an emphasis on its current significance. The aim was not to exclude interpretative, scholarly or historical accounts of Kant's thought, for these provide the only sound basis for any current interest in it, but rather to focus and extend that current interest. It was, however, agreed that it would be more informative to offer brief, illustrative, reviews of Kant's relevance to current epistemology, moral philosophy and political thought rather than merely to repeat that bland general view. Accordingly this first essay reviews some aspects of Kant's epistemology, while later issues will contain similar accounts of his moral philosophy and political thought.

To give any priority to the current impact of Kant's philosophy would make sense only if two conditions are met. The first requires that there is a valuable and legitimate reference to Kant in current philosophical debates: The second requires acknowledgment of the limitations attaching to any such appeal. The eighteenth-century climate in which Kant worked provided philosophical, scientific, and social conditions which differ greatly from those of the late twentieth century. Although the point has not been much emphasized recently, ${ }^{1}$ it is an ancient objection to Kant's epistemology that it was overinfluenced by the science of his time. Feminist writers have rightly pointed to eighteenth-century social mores which may explain, but not excuse, views about the sexes which Kant held but which we find incongruous and unpalatable. ${ }^{2}$ Philosophy has also changed, but cannot divorce itself from the historical tradition as easily as the 
sciences. There are still recognizable similarities between some contemporary debates and those of earlier centuries. It would be remarkable if Kant's ideas fitted exactly into the debates of his philosophical successors 200 years later, but it would be remarkable if there were no such connections.

It is particularly important to mark those inevitable limitations because Kant's impact on current philosophy is so extensive. Of all the historical figures in the modern philosophical tradition it seems likely that Kant has been the most influential in the West in recent years. Almost every philosopher writing on current issues feels obliged to make some reference to Kant, hostile or approving, well or ill informed. ${ }^{3}$ Even if that is recognized, however, still the grounds for a current interest vary from philosopher to philosopher and are often not spelt out. In this brief review I would like to make some of those grounds in epistemology more explicit and draw attention to some of their limitations. Among the topics that deserve discussion are those of 'holism', 'intentionality' and 'cognitive science', but it is not possible to consider all of them. I therefore restrict myself to a general point about Kant's overall project in the first Critique and to some discussion of holism in Kant and current philosophy.

\section{A Common Framework: Rejecting the Tradition}

The philosophical situation which Kant inherited at the end of the eighteenth century was similar to that which faced Russell a century later. ${ }^{4}$ Kant had the advantage of overseeing 150 years of traditional philosophy from Descartes to Hume, even if he did not have full access to all the printed works of his predecessors. Russell was able similarly to oversee the course of philosophy throughout the nineteenth century up to the development of British idealism. Both Kant and Russell initially accepted the prevailing orthodoxies, the Leibniz-Wolff philosophy and a Bradleyan idealism respectively, and both came dramatically to reject them. Kant's Preface (A) to the first Critique deserves to be compared with the account Russell gave of his philosophical development in the 1924 essay on 'Logical Atomism'. Kant spoke of 'metaphysics as the battleground of endless controversies' (Aviii) and of his own aims as those of its 'reform and restoration' (Ax), and famously also of 'revolutionising metaphysical procedure' (Bxxii). Russell spoke of himself as a 'disciple of $\mathrm{Mr}$ 
Bradley' and of a change of view which 'shattered the whole foundation for the metaphysics' of earlier traditional philosophers. That change led him to apply a new logic to his old problems 'which proved far more fruitful than that of traditional philosophy'. Both Kant and Russell consciously represented their break with existing tradition as a revolution in philosophy, and both had a powerful influence on their immediate successors, even though they may not have approved of those later views. It is an irony, yet understandable, that with such a similar background Russell seemed not to see the common ground they shared and remained among Kant's most hostile critics. ${ }^{6}$ For Russell measured his difference from Kant in the field of philosophy of mathematics, and saw the rest of Kant's philosophy through the distorting lens of the nineteenth-century commentators.

Partly as a result of Russell's influence, the development of twentieth-century analytic philosophy proceeded without much reference to Kant until the period after the Second World War. At that time, after the Russellian revolution had been much discussed and criticized, it began to be seen that there was common ground between the Russellian and the Kantian revolutions. It began to be understood how significant were the revolutionary changes which both Kant and Russell canvassed in a direction away from the assumptions of traditional philosophy. The traditional philosophy which Kant sought to supersede at the end of the eighteenth century was not very different from the traditional philosophy which Russell wished to replace at the beginning of the twentieth century. British idealism was still an idealism of some form and rested some of its central debates, such as that between monism and pluralism, on traditional sceptical arguments. ${ }^{7}$ It is another, and less understandable, irony that Russell himself, for all his revolutionary aspirations, remained wedded to a markedly traditional agenda in epistemology. ${ }^{8}$ After the Second World War, and when Russell's own position was better appreciated, other philosophers such as Wittgenstein, Ryle, Austin and Rorty, moved more vigorously and more self-consciously away from that traditional agenda. Those representatives did not all move along the same trajectory, but even when they were not wholly aware of it, some were following a path which Kant had advocated much earlier.

The tradition which Kant recognized and rejected was complex. $\mathrm{He}$ seems to have thought of it as one dominated by a search for a justified foundation for knowledge which either dogmatically transcended our cognitive powers or sceptically denied them. But if 
his own general account of the position is accurate it can be represented by two doctrines:

(1) A Cartesian idealism in which all experience is grounded in personal, subjective, mental occurrences. These can be called 'representations ${ }_{1}$ ' or 'ideas'.

(2) An empiricist scepticism which denied an adequate justification for ordinary and scientific beliefs.

This way of representing the tradition does not exactly match Kant's own distinctions between dogmatism and scepticism or between rationalism and empiricism. But those contrasts conceal an assumption, namely (1), on which all the contrasted theories depend. Kant's contrasts can easily be reinstated within this framework, so long as provisos are made to avoid identifying his two distinctions. Rationalism and empiricism do not correlate exactly with dogmatism and scepticism respectively.

Kant's attitude to the theories in his two distinctions is certainly not the popular undergraduate idea that he reconciles those oppositions. It is instead one of re-orientating philosophy so that neither of the opposed positions remains an option. In this most general issue, as in the more detailed criticism of earlier philosophers in the Dialectic, Kant anticipates Wittgenstein's technique of rejecting opposed theories on the grounds that they both share an assumption which itself ought to be rejected. Kant is not accepting the traditional framework and answering its questions within that framework. He questions, and changes, that framework itself so that those questions no longer arise. His procedure is parallel to that of McDowell in Mind and World, ${ }^{10}$ where the opposition between Davidson's coherentism and Evans's realism is avoided by an adjustment in the assumptions at an earlier stage. Davidson and Evans are criticized for adopting unstable positions which lead to an interminable oscillation between an unsatisfactory coherentism and a 'Myth of the Given'. Although that opposition between Evans and Davidson does not exactly match Kant's contrast between dogmatist and sceptic, McDowell is surely right to represent Kant's position as directly relevant to that current issue. Kant's imagery of the oscillation between dogmatism and scepticism is close to McDowell's, whose views are consciously represented, like Kant's, as a way of finally abandoning certain forms of traditional philosophy. There is here good reason to claim that the 
dissatisfaction with the tradition which Kant expressed at the end of the eighteenth century is essentially the same as that which McDowell expresses at the end of the twentieth.

Kant's rejection of (1) and (2) indicates both his deviation from the tradition and the new path for philosophy that he recommends. He evidently thought that the Cartesian empirical idealist had erred in giving a priority to inner over outer experience; and he equally believed that sceptical empiricists had erred in failing to admit the nature and range of non-empirical, a priori, principles in our experience (B795). In his argument for the former, in the Refutation of Idealism (B274-9), Kant is engaged in issues of the priority, or dependence, between elements in our experience, and seeks to correct the earlier Cartesian assumption (1) that inner experience is prior to outer. In his account of the latter he canvasses a new way of representing our experience as one necessarily governed by rules which constitute that experience. To identify such rules as themselves a priori is to allocate the highest priority to them within the framework of experience.

In both of these responses Kant implements what can be called, following Strawson's term, a 'descriptive metaphysics'."1 Kant's central project in the first Critique is, as he claims, that of constructing an 'inventory of our possessions through pure reason' (Axx) which will map, demonstrate and correct those relations of dependence and priority among items in experience. Kant's conception of such a project is, I believe, not a direct argument against traditional scepticism, for that would make too much of a concession to the rejected tradition. Instead it offers a neutral, accurate, description of salient aspects of that experience, with the indirect idea of showing in some cases that traditional philosophers had misdescribed or misunderstood those aspects. That is, for example, the structure of the argument in the Refutation of Idealism. In this way he advocates a project which points in a direction away from the tradition and towards a current interest. Although Kant's conception of 'descriptive metaphysics' is not the same as Strawson's, nevertheless both share this common ground. In that general project, as also in more specific attempts to mark dependence relations among items in experience, Kant has more in common with late twentiethcentury philosophers than with his traditionalist eighteenth-century predecessors or their nineteenth-century successors.

Such a link with the twentieth century carries with it an evident limitation. Few philosophers have seriously attempted to map the 
whole of our experience, or even, like Kant or Strawson, to map its most general, governing, principles. The logical positivists' programme of 'rational reconstruction', for example, was aimed initially at the mapping of specific branches of science rather than the whole of experience. Philosophical cartography has been typically local and determined by current interests, often derived from other nonphilosophical disciplines. It may be thought that a clear map of the terrain in some developing science would be more valuable than one of our ordinary folk experience, and current interest in such a discipline as cognitive science provides a recent example. In that context it has been claimed that Kant's views are relevant to the current debates, ${ }^{12}$ but it cannot be expected that such current interests will always be echoed in Kant.

A further, and controversial, limitation which might be urged is that this picture of Kant's descriptive metaphysics is too charitable. It will be said that however much he wished to escape from the tradition he nevertheless fell prey to it in what has been called by McDowell and Strawson the 'dark side' of his philosophy. ${ }^{13}$ This is a substantial issue about the basic interpretation of Kant's work which cannot be considered here: I restrict myself to two points. It will be said that Kant's descriptive metaphysics was not in any case a novelty since something of that kind had been done already by Locke. But here the plain answer is that Locke's psychological survey is recognized by Kant as a project of a different kind. Not only does Kant distance his own account from Locke's empirical psychology (Aix-x; B118-19); he also makes it clear that his central account of what makes experience possible is not intended as a psychological or causal account (B124-6). These restrictions narrow down the scope for Kant's descriptive metaphysics and point in a direction which twentiethcentury philosophers can understand. The project is a descriptive metaphysics and not a descriptive folk psychology.

The second issue arises directly from the thought that Kant's own terminology of 'representations' and his account of a priori aspects of experience as subjective and mind-dependent commit him to some version of the tradition's assumption (1). Kant is undeniably committed to some form of idealism, but this leaves open the question how far his version deviates from that tradition. Although Kant makes it plain that he is not a traditional (material, empirical) idealist a more positive, detailed, characterization of his idealism remains open. Kant undoubredly locates his project within the scope of 
'representations', speaks of appearances as 'representations', and does claim that a priori aspects of experience are in some way minddependent. But we cannot conclude from this that Kant remains simply committed to the Cartesian tradition. Such a commitment would arise only if Kant used these claims within a dualist framework in which we have a bare opposition between what is mind-dependent and what is mind-independent. Such an exhaustive opposition is still common among contemporary philosophers. There is a temptation for commentators to tax Kant with this commitment on the assumption that such a dualist framework is unavoidable, or at least unavoidable for Kant, but to argue in that way is to beg the question. ${ }^{14}$ It was for that reason that I represented assumption (1) in terms of a specific sense for the term 'representation,'. I think it important to leave open the question whether Kant's own use of such terms is different, should be marked as 'representation 2 ', and so does not commit him to a traditional dualism. Even if that is so, however, we need to know whether there are grounds for denying that Kant himself deployed that terminology and those claims within a dualist framework. My own belief is that he makes clear at many points in the Critique that his aim was precisely to reject such a traditional dualism. In that case, though the issue remains to be further explored, there is reason to deny that the cited features commit Kant to any traditional understanding of assumption (1).

These points connect Kant to recent philosophy at the most general level and at several points, but they do not yet show that Kant has a contribution to make to them. With hindsight we may be able to see how some claim of Kant's can be interpreted in the light of current views, but if the connection stopped there, then there would be no reason to think that Kant's own views are helpful in those current debates. However, in this general account there is more than a suggestion that Kant's position and his arguments can offer such a contribution and this can be illustrated from the work of McDowell and Quine. Their projects do not exhaust current epistemology, but each is representative of a recent style of analytic philosophy, Quine following Russell and McDowell Wittgenstein and the Oxford philosophers. McDowell's appeal to a central relationship between sense and understanding in Kantian epistemology offers one such example, and Quine's account of holism offers another.

There is a connecting link between these two accounts. For Kant experience has to be seen as an interplay between elements of 
different kinds, for example between a posteriori and a priori elements. The famous passage at B75 which expresses the indispensability for experience of both sense and understanding, intuitions and concepts, is a striking expression of one aspect of that interdependence. That interdependence is a typical aspect of Kant's holism, and it was that aspect which encouraged McDowell to find in Kant a version of his own view that sense experience cannot be divorced, even notionally (Mind and World, p.98), from understanding, from concepts, or from what he calls, following Sellars, 'the space of reasons'. McDowell's central thesis is that recognition of such an interdependence not only throws light on the psychological framework of human experience, but also offers the best way of correcting the traditional dualism outlined above in (1) and (2).

Even here, however, there is some ambiguity in McDowell's account of Kant. One way of taking these Kantian claims would be to make a crucial distinction between sense and understanding, but then to insist on a mutual dependence between their contents. A second way would be to hold that the interdependence between them means that they cannot be separated even notionally. The former claim would at least allow a notional separation which the latter rejects. McDowell himself adopts the latter, stronger, view, and rejects the former, weaker, claim which can be associated with Evans's form of realism. McDowell himself rejects Evans's view partly on the ground that it concedes too much to a 'Myth of the Given', but it might be questioned whether Evans is vulnerable to such an objection. It remains therefore an open question whether Kant himself is closer to the stronger or the weaker claims; closer, that is, to McDowell or to Evans. And it remains an open question of some current interest which of these positions is correct. Kant is inescapably involved in these issues, since he occupies one of the candidate positions.

In some such ways as these the project and attitude of descriptive metaphysics is relevant to current debates and deserves to be further explained and pursued. It needs a clearer methodology in outlining the procedures Kant envisaged for what he called a 'transcendental topic' (B324), and for the style of argument that has come to be called 'transcendental argument'. ${ }^{15}$ But to elucidate these Kantian notions can no longer be seen as a domestic issue in Kant-interpretation of only historical interest. If it is right to suggest that Kant's project is radically opposed to an epistemological tradition whose assumptions continue to be made, then attention to that project may enable us to 
abandon that tradition once and for all. Even in these most general terms Kant encourages us to pursue his project and thereby to abandon the same traditional framework which he rejected.

\section{Holism}

Kant's commitment to some form of holism, in which experience or its salient features is regarded as a systematic whole, is apparent at many points in the Critique. The project, noted above, to criticize and map the role of reason in experience, his descriptive metaphysics, was associated with the requirement that this should be treated in a systematic way. That requirement is manifested most obviously in the 'architectonic' plan which the project followed, and illustrated clearly in the implied complaint in the metaphysical deduction, that Aristotle's discussion of categories was a haphazard search guided by no principle (A81). It is evident in Kant's discussion in the Dialectic of the idea of 'systematic unity' and of its central role in science and experience (B670-732) and in his consistent appeal to such a notion throughout the Critical philosophy, for example in the third Critique (Akademie edition 20: 209). More particularly, it is evident in the many examples of mutual interdependence which the project of descriptive metaphysics reveals. One of the most fundamental of these, the interdependence between sense and understanding (B75), was noted earlier in the reference to $\mathrm{McD}$ owell, and another is the interdependence between a conceptual and a personal unity in transcendental apperception. But there are so many that it is hard to avoid the conclusion that such holistic tendencies are a trade mark of Kantianism.

These claims, however, have two limitations. The first is that other philosophers had also emphasized systematic relations between elements in experience, and had also planned their own philosophical enquiries on a systematic basis. Kant's convictions of these kinds are not unique to him. The second is that such patent illustrations of holistic tendencies tell us neither what it is to be holistic nor in what specific contexts Kant's holism is canvassed. We are used nowadays, for example, to distinguishing epistemological and semantic holism among others ${ }^{16}$ and these have been given both an extensive airing and a detailed characterization in the work of philosophers such as Quine. If Kant's holism is to be anything more than a bare 
recognition of experience as a system, or only a conscious advocacy of a systematic method, then these limitations have to be overcome. In what follows I concentrate on epistemological rather than semantic holism, although there is some overlap between the two contexts.

One way of beginning to meet the requirement to make Kant's holism more precise would be to contrast Kant's approach to experience with that of his empiricist predecessors. Traditional empiricists thought of experience, and of the language which expresses it, as an analytic construction out of elementary, atomic, contents. The complex constituents of a developed experience, or language, depended upon the ultimately simple atoms from which they were constructed. Even a later empiricist like Russell followed a similar one-way foundationalist construction in the epistemology of logical atomism, and he deserves for that reason to be characterized as a traditional philosopher. It is quite clear, however, that Kant's epistemology repudiates any such one-way dependence of complex items on simple ones. It is not that Kant denies such an empiricist dependence; he accepts it but believes that it tells only half the story. He supplements the empiricists' one-way dependence with a two-way interdependence between the lowest level and the highest level items in experience. This departure from the empiricists is evident both in the epistemological and the semantic context. The empiricist one-way dependence of complex concepts on simpler may be seen as a semantic picture associated with a verificationist account of meaning. Kant's account of meaning is not verificationist, and he does not subscribe to the view that linguistic meaning is exhausted by the relationship between complex and simple concepts. Both claims are consequences of his emphasis on the two-way relationship. The second claim is made clear in the metaphysical deduction (B91-5) where Kant anticipates later philosophers, like Quine, in canvassing a priority of judgements or propositions over their subpropositional constituents.

For Kant, too, one significant difference between the lower and higher level elements in epistemology or semantics is that the former are a posteriori and the latter a priori. A posteriori elements in experience require a priori categories to fit them into a coherent system, and the categories need a posteriori sense elements in order to give them a full, schematized, meaning or reference. Kant distinguishes his own view from empiricism not only by offering a twoway dependence in place of a one-way dependence, but also by 
characterizing the categorial level as a priori in a way which traditional empiricists could not have accepted.

That more detailed Kantian account of epistemological holism echoes the views of Quine in still other ways. Quine does not renounce empiricism, but, like Kant, he rejects its traditional forms, and he is influenced, like Russell, by a more sophisticated treatment of logic and language than was available to Kant. But Quine's holistic picture of experience in 'Two dogmas of empiricism'17 where high level, abstract, principles interact with low level sense experiences to form a global structure has the same shape as Kant's. It expresses an interdependence between these elements, and not, like traditional empiricism, a one-way dependence of principles on sense experience. Quine underlines that mutual relationship in allowing a choice when faced by recalcitrant experiences to adjust either the abstract principles or the lower level sensory beliefs. At this point the differences between the two accounts begin to seem more significant than the similarities. Quine's account of the way in which even the most abstract, formal, and apparently self-evident principles may be responsive to sense experiences expresses a residual empiricism which Kant could not accept. The point is implicit in Quine's rejection of the distinction between analytic and synthetic truth, which marks a further difference from Kant. For it is the former class of truths which may be thought invulnerable to recalcitrant experiences. The fact that such a rejection differentiates Quine also from the traditional empiricists does not bring him any closer to Kant.

In Quine's later Word and Object ${ }^{18}$ a Kantian picture emerges again. For Kant's appeal to high-level categorial principles as constituting the central structure of experience is matched by Quine's appeal to 'analytical hypotheses' in completing the reconstruction by a field linguist of some native language from behavioural data. There is, once again, the same recognition of the role that such categories play in determining the nature of experience. Quine's new account may seem to bring him even closer to Kant. For the ultimate analytical hypotheses between which the field linguist has to choose, in giving sense to the native utterances, float free of the basic behavioural data. Even when all possible data are available these still do not fix any unique choice of analytical hypotheses. According to Quine there is reason to suppose that the data will be equally well accommodated by any number of alternative, incompatible, categorial schemes. Although this radical indeterminacy of translation is claimed by 
Quine to be different from the more general claim for the underdetermination of theory by data, the two doctrines evidently share common ground. This may seem to distance Quine's conception of such principles from the earlier residual empiricism and to make his position closer to Kant, but this turns out to be an illusion. Quine's analytical hypotheses, which float free from the data, are not to be assimilated to Kant's a priori categorial principles for one evident reason. Whereas Quine envisages any number of alternative analytical hypotheses Kant does not allow any such flexibility for his categories. For Kant there is just one central system of categorial principles which govern our experience, and no possibility of their replacement by any alternative set. Because his categories uniquely make experience possible, any alternative system would be strictly unintelligible.

The stability of Kant's system of categories derives, however, from two different sources, one of which is compatible with Quine's account. On one side it is stable simply because it is the outcome of the project of descriptive metaphysics, that is, it maps the salient features of our experience. Our experience has that stability whether or not there are alternative possible schemes that might replace it. The actual stability of our experience is not compromised by the existence of other possible schemes. Even Quine is in no doubt that the existence of innumerable analytical hypotheses need not prevent the field linguist from selecting his preferred hypothesis to give a practical sense to the native language. ${ }^{19}$ If it is possible at all the linguist will simply choose the hypothesis which is closest to home, that is, which is most readily understood in terms of his own language and experience. That resolution of the issue does not serve to disqualify alternative hypotheses, for they are all claimed to be just as adequate to the behavioural data. The field linguist's resolution of the issue rests on no rational assessment of the evidence for or against the alternative hypotheses, but simply on the inevitability of choosing his own scheme. In this line of argument Quine and Kant can still agree on the stability of that home scheme.

The other ground of the stability of Kant's principles is derived from his belief that they can all be proved to be necessary if experience is to be possible. That line of argument does disqualify any alternative schemes, and is both vulnerable and incompatible with Quine's position. It is vulnerable to the earlier noted complaint that Kant's supposedly unique principles reflect only the science of his time, and so are not strictly unique at all. Some commentators have 
been willing to defend Kant against that objection by claiming that the principles are metaphysical rather than scientific. ${ }^{20}$ They would then be more general than the eighteenth-century scientific principles which fall under them, and it might then be possible to accommodate even twentieth-century science within their framework. The position is still not wholly clear. Kant himself indicates that his a priori principles are more general than the science which exemplifies them (B201-2), but that provides little guidance in relating them to twentieth-century science. On the other side even Quine's alternative analytical hypotheses do not obviously violate the requirements which Kant's principles impose. Undetached rabbit parts are presumably subject to causal influences just as rabbits are. Nevertheless Kant's belief in a fixed, and stable, provably unique metaphysical framework for ordinary experience and science is at odds with the Quinean picture and vulnerable to its claims.

Quine's own position is itself, however, not quite invulnerable. Quine's account of a range of free-floating analytical hypotheses may be represented as a return to traditional scepticism. The suggestion is that the field linguist who selects his final theory in terms of his own preferred categories is acting understandably but arbitrarily. His procedure may seem to be a second-best alternative, issuing in theories which have only a flawed claim to truth. Genuine truth, it might be said, is available to us only if we have some guarantee that there is ultimately no such range of alternative hypotheses, so that our theorizing will converge on some single ultimately true theory. If it is further claimed that every theorist is subject to the same constraints this may be seen less as a consolation than as a reinforcement of the sceptical view that there is something second-best and flawed about our theory construction.

Quine's own intentions may well not have been sceptical in this way, but the picture encourages such scepticism. The potential lack of convergence in science towards one ultimate true theory may seem to pose a threat to any adequate conception of empirical truth, but this is open to question. In Kant's terminology the supposed ultimate truth would be transcendent and therefore something that we neither should, nor rationally could, be concerned about. For Kant questions of truth are properly only immanent and not transcendent; they concern the internal truths of our experiential framework and not any ultimate truth, with a capital $\mathrm{T}$, outside it. Only two provisos need to be made to such a claim. First Kant recognizes the special role, and special truth, of the a priori constitutive principles, and second he 
recognizes in the regulative Idea (Idee) of a systematic unity in nature (A647/B675) a necessary maxim in scientific enquiry. But neither of these provisos reinstates any transcendent conception of truth. The special truth of the a priori principles is to be explained only in terms of their role in experience. It is transcendental, but immanent and not transcendent. And the idea of systematic unity in nature is deliberately treated by Kant as only a regulative and not a constitutive principle. It is not something we could establish as true, and may be strictly beyond our powers to recognize. The most we can say is that it is inevitable, and valuable, as a working assumption in scientific practice. If, for Quine, the potential failure of convergence on some ultimate truth is a threat to empirical knowledge, then Kant would disagree. ${ }^{21}$ Both Quine and Kant accept an epistemological holism but they differ in the consequences to be drawn from it. Kant's holism rejects empiricism and its sceptical tendencies; Quine's holism retains an improved empiricism, but is liable to the same sceptical tendencies as the traditional version. It is not yet obvious which of them is right.

The specific topics sketched here were intended not to resolve issues about Kant's position but to indicate how that position bears on current issues. The discussion illustrates a range of controversial issues about interpreting Kant, about comparing him with contemporaries, and about evaluating the outcome. Typically that evaluation addresses current problems and offers distinctively Kantian ways of resolving them. It is a central goal of Kantian Review to encourage such discussion and evaluation.

\section{Notes}

1 In Paolo Parrini (ed.), Kant and Contemporary Epistemology (Dordrecht: Kluwer, 1994), Peter Mittelstaedt, Gordon Brittan, and Vittorio Mathieu offer some defence against this objection. Stefan Körner, however, maintains his long-standing doubt whether Kant can overcome it. The best recent account of that doubt is Michael Friedman's Kant and the Exact Sciences (Cambridge, MA: Harvard University Press, 1992).

2 For example in Jean Grimshaw, Philosophy and Feminist Thinking (Minneapolis, Minnesota University Press, 1986); Carole Pateman, The Sexual Contract (Stanford, CA: Stanford University Press, 1988), and Barbara Herman, 'Could it be worth thinking about Kant on sex and marriage?', in L. Antony and C. Witt, A Mind of One's Own (Boulder, Westview Press, 1993). 
3 Several philosophers, such as Heidegger, Deleuze, Putnam and Strawson, have been strongly influenced by Kant in their own independent work.

4 I treat Russell as a representative of a general trend against the tradition at the end of the nineteenth and start of the twenticth century. Many others, such as William James, Moritz Schlick, G. E. Moore, and E. Husserl played a part.

5 Logic and Knowledge, ed. R. C. Marsh (London: Allen and Unwin, 1956), p.324.

6 'Logical Atomism', ibid., p.324: Russell says that 'stock philosophical arguments about mathematics (derived in the main from Kant) had been rendered invalid by the progress of mathematics'. But the later History of Western Philosophy showed the same hostility.

7 See F. H. Bradley, Appearance and Reality (Oxford, 1893), ch.2.

8 See Russell's 'Lectures on the philosophy of Logical Atomism', Monist (1918-19), reprinted in Logic and Knowledge, and The Problems of Philosophy (London, 1912). Russell's revolution was one mainly of method, but his agenda and problems remained traditional.

9 Wittgenstein even in his Tractatus phase wanted to go beyond Russell, and his later philosophy must have seemed to Russell even more revolutionary and was generally recognized as such. Austin's and Ryle's revolutionary aspirations have been less generally appreciated. See my entries on both in Jonathan Dancy and E. Sosa (eds.), A Companion to Epistemology (Oxford: Blackwell, 1992), 34-6 and 452-4. Rorty's rejection of the tradition is evident in such works as Philosophy and the Mirror of Nature (Oxford: Blackwell, 1980) and Contingency, Irony, and Solidarity (Cambridge: Cambridge University Press, 1989).

10 J. McDowell, Mind and World (Cambridge, MA: Harvard University Press, 1994).

11 P. F. Strawson, Individuals (London: Methuen, 1959), and Scepticism and Naturalism (London: Methuen, 1985). It would be wrong to assume that Strawson's conception of descriptive metaphysics was the same as Kant's; even the later work although closer to Kant still differs from him at some points. See also 'The problem of realism and the a priori' in Parrini (ed.), Kant and Contemporary Epistemology.

12 Kant's relation to cognitive science has been explored in Patricia Kitcher's Kant's Transcendental Psychology (Oxford: Oxford University Press, 1990), and Andrew Brook's Kant and the Mind (Cambridge: Cambridge University Press, 1994).

13 The Bounds of Sense, 'The metaphysics of transcendental idealism', pp. 235-76. Mind and World, p.41.

14 I think Paul Guyer is at least in danger of this in his Kant and the Claims of Knowledge (Cambridge: Cambridge University Press, 1987), pp.333-44. I discuss the passage in 'Tradition and revolution in Kant', 
Proceedings of the Eighth International Kant Congress (Memphis: Marquette University Press, 1995), pp.1119-36.

15 S. Kripke's Naming and Necessity (Oxford: Oxford University Press, 1980) developed a classification scheme in his account of modal logic which has more in common with Kant's scheme than either the empiricists' restriction to a simple 'analytic/synthetic' division, or a Quinean rejection of that distinction. Current interest in 'transcendental arguments' is not simply a domestic issue for those interested in Kant. See, for example, J. Fodor and E. LePore, Holism: A Shopper's Guide (Oxford: Blackwell, 1992).

17 In W. V. O. Quine, From a Logical Point of View (Cambridge, MA: Harvard University Press, 2nd edition, 1964).

18 W. V. O. Quine, Word and Object (Cambridge, MA: MIT Press, 1960).

19 Word and Object, pp.73-9. There Quine denies that the field linguist's resolution of his problems is 'capricious', but insists on the limitations imposed by his choice of analytical hypotheses, namely that there is no 'fact of the matter'. See Fodor and LePore, Holism, for criticism of Quine's views, and Louise Antony, 'Meaning and semantic knowledge', Aristotelian Society, Supplementary volume 71 (1997).

20 The contributions cited earlier, n.1, from Parrini (ed.), Kant and Contemporary Epistemology, discuss the issue. See also Michael Friedman, 'Kantian themes in contemporary philosophy', to appear in the Aristotelian Society Supplementary Volume 72 (1998). Friedman argues for the inseparability of Kant's epistemology from his eighteenthcentury conception of science, and connects this to a Quinean 'naturalized epistemology'.

21 Richard Rorty's rejection of a traditional epistemology and of any conception of truth as correspondence can be seen as a response to a Quinean position. See, for example, his 'The contingency of language' in Contingency, Irony, and Solidarity (Cambridge: Cambridge University Press, 1989). There Davidson's treatment of truth is applauded as 'the first systematic treatment of language which breaks completely with the notion of language as adequate or inadequate to the world' (p.10). 